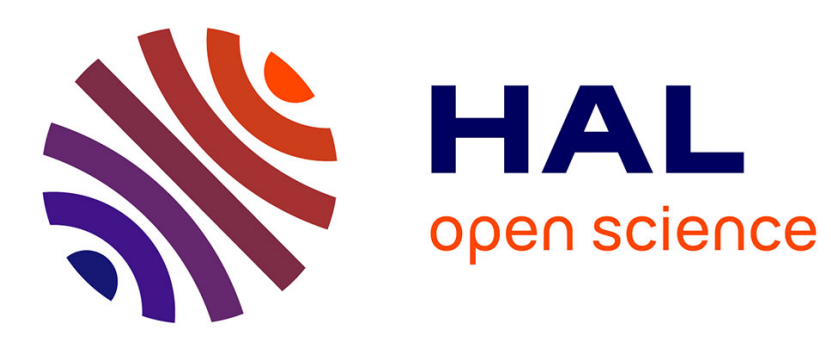

\title{
CO dissociation on Pt-Sn nanoparticles triggers Sn oxidation and alloy segregation
}

\author{
A. Moscu, C. Theodoridi, L. Cardenas, C. Thieuleux, D. Motta-Meira, G. \\ Agostini, Y. Schuurman, Frédéric Meunier
}

\section{- To cite this version:}

A. Moscu, C. Theodoridi, L. Cardenas, C. Thieuleux, D. Motta-Meira, et al.. CO dissociation on PtSn nanoparticles triggers Sn oxidation and alloy segregation. Journal of Catalysis, 2018, 359, pp.76-81. 10.1016/j.jcat.2017.12.035 . hal-01737912

\section{HAL Id: hal-01737912 \\ https://hal.science/hal-01737912}

Submitted on 26 Jul 2021

HAL is a multi-disciplinary open access archive for the deposit and dissemination of scientific research documents, whether they are published or not. The documents may come from teaching and research institutions in France or abroad, or from public or private research centers.
L'archive ouverte pluridisciplinaire HAL, est destinée au dépôt et à la diffusion de documents scientifiques de niveau recherche, publiés ou non, émanant des établissements d'enseignement et de recherche français ou étrangers, des laboratoires publics ou privés. 


\title{
CO dissociation on Pt-Sn nanoparticles triggers Sn oxidation and alloy segregation
}

\author{
Alina Moscu ${ }^{\mathrm{a}, \mathrm{b}}$, Christina Theodoridi ${ }^{\mathrm{a}}$, Luis Cardenas ${ }^{\mathrm{a}}$, Chloé Thieuleux ${ }^{\mathrm{b}}$, Debora Motta-Meira ${ }^{\mathrm{c}}$, \\ Giovanni Agostini ${ }^{c}$, Yves Schuurman ${ }^{\mathrm{a}}$, Frederic Meunier ${ }^{\mathrm{a}, *}$
}

\footnotetext{
a Institut de Recherches sur la Catalyse et l'Environnement de Lyon, IRCELYON, Université Lyon 1, CNRS, 2, Av. Albert Einstein, 69626 Villeurbanne, France ${ }^{\mathrm{b}}$ Université de Lyon, Institut de Chimie de Lyon, LC2P2, UMR 5265 CNRS-CPE, Lyon-UCBL, CPE Lyon, 43 Bvd du 11 Novembre 1918, 69100 Villeurbanne, France ${ }^{\mathrm{c}}$ European Synchrotron Radiation Facility (ESRF), 6 Rue Jules Horowitz, BP 220, Grenoble Cedex 9 38043, France
}

\begin{abstract}
Identifying the causes of the segregation of Pt-based alloy nanoparticles is crucial for the design and operation of the corresponding catalysts and electrodes. This article describes a yet unreported mode of alloy segregation upon exposure to CO. In situ IR studies indicated that Pt-Sn alloy nanoparticles were not stable under (i) $\mathrm{H}_{2}$-free $\mathrm{CO}$ at any temperature or (ii) $\mathrm{CO} / \mathrm{H}_{2}$ mixtures at temperatures below ca. $450 \mathrm{~K}$. This was rationalized by the ability of Pt to dissociate $\mathrm{CO}$. The oxygen adatoms readily reacted with metallic Sn to form a SnOx species, leading to Pt-Sn segregation, alongside carbon deposition. XPS and XANES analyses confirmed $\mathrm{Sn}$ reoxidation. While a contamination by traces of $\mathrm{O}_{2}$ at the sub-ppm level cannot be excluded, the data reported indicate that the structural modifications undergone by the Pt-Sn nanoparticles are more consistent with a reaction involving $\mathrm{CO}$ rather than one involving $\mathrm{O}_{2}$. In particular, the XPS analysis after CO exposure revealed an increased fraction of graphitic carbon, while that of oxidized carbon decreased. Thermodynamic calculations indicate that the oxidation of tin by $\mathrm{CO}$, with concomitant carbon formation $(\mathrm{Sn}+\mathrm{CO} \rightarrow \mathrm{SnO}+\mathrm{C})$ is as favourable as Boudouard reaction $\left(2 \mathrm{CO} \rightarrow \mathrm{CO}_{2}+\mathrm{C}\right)$ at low temperatures. Alloy stability in the presence of $\mathrm{CO}$ must therefore be a concern when $\mathrm{CO}$ dissociation is possible and one of the alloyed metal is oxophilic.
\end{abstract}

\section{Introduction}

Alloy nanoparticles receive ever-increasing interest as catalyst and electrode materials with structural properties that can largely differ from those of bulk samples [1]. The composition and ordering of the surface of as-prepared alloys may differ from those existing in the sample bulk [2,3]. More, alloy nanoparticles may readily decompose or restructure under conditions of use due to the presence of some reactive or strongly adsorbing molecules [4-12]. Alloy segregation induced by oxidation appears to be a process of utmost complexity $[2,13]$. A first segregation mode can be referred to as "adsorbate-induced surface segregation". The adsorption of CO was shown to lead to surface segregation over many materials, due to the preferential formation of strong chemical bonds between $\mathrm{CO}$ and one of the metals present in the alloy, e.g. Pd in the case of a Au-Pd catalyst [14] and Pt in the case of a Pt-Co electrode [9]. A second segregation mode of alloys involves the reoxidation of one or more of the metal components by strong oxidizers such as $\mathrm{O}_{2}$.

\footnotetext{
* Corresponding author.

E-mail address: fcm@ircelyon.univ-lyon1.fr (F. Meunier).
}

Pt-Sn nanoparticles were shown to be readily converted into an intimate mixture of metallic Pt clusters and oxidic tin domains during the oxidation of $\mathrm{CO}$ [15] and during the preferential oxidation of $\mathrm{CO}$ in the presence of large excess of $\mathrm{H}_{2}$ (PROX) [16].

Pt-Sn alloy is the crucial component of an industrial catalyst for the production of alkenes from alkanes [17,18] and is also a promising electrode material for Proton-Exchange Membrane Fuel Cells (PEM-FC), as $\mathrm{Pt}_{3} \mathrm{Sn}$ supported on carbon showed much improved resistance to $\mathrm{CO}$ poisoning as an anode electrocatalyst as compared to Pt and many other alloys [4,19]. The improved resistance to $\mathrm{CO}$ poisoning was later attributed in part to lower CO adsorption coverage on the Pt sites [20]. The heat of adsorption of CO on Pt in Pt-Sn alloy nanoparticles is ca. $95 \mathrm{~kJ} \mathrm{~mol}^{-1}$, while a value of $180 \mathrm{~kJ} \mathrm{~mol}^{-1}$ is reported on pure Pt [6].

We reported in an earlier paper [6] a segregation process that took place over alumina-supported Pt-Sn nanoparticles under a $\mathrm{CO} / \mathrm{H}_{2}$ mixture, which occurred only below ca. $450 \mathrm{~K}$ and appeared to be reversible when temperature was raised back above $450 \mathrm{~K}$. The origin of this segregation was unclear and we report here a thorough investigation on this matter. We demonstrate that a yet unreported mode of segregation took place, involving CO 
dissociation with subsequent reoxidation of the non-noble metal leading to the decomposition of the alloy phase.

\section{Results and discussion}

The alumina-supported Pt and Pt-Sn samples were prepared using a colloid-based method reported earlier [6,21] (Exp. Section and Supporting Information). The narrow particle size distribution was centered around $1.8 \pm 0.4 \mathrm{~nm}$ (Fig. S1). The global composition based on ICP was $0.37 \mathrm{wt} \% \mathrm{Pt}$ and $0.23 \mathrm{wt} \% \mathrm{Sn}$. The nature of the alumina-supported Pt-Sn particles was investigated by in situ diffuse reflectance spectroscopy. CO adsorption can be used to reveal the nature of the sample surface, as markedly different band positions are obtained whether Pt is alloyed with Sn or not $[4,22]$. The IR stretching band of $\mathrm{CO}$ adsorbed on pure metallic Pt at $498 \mathrm{~K}$ under a mixture of $\mathrm{CO}$ and $\mathrm{H}_{2}$ was located at ca. $2070 \mathrm{~cm}^{-1}$ (Fig. 1A), while that adsorbed on a Pt atom of a Pt-Sn alloy absorbs at ca. $2046 \mathrm{~cm}^{-1}$ (Fig. 1B). It should be stressed that $\mathrm{CO}$ adsorption on metallic tin is negligible in the present conditions [23], so all the carbonyl bands observed were related to surface Pt atoms only.

Our earlier study showed that the alloy was stable under a $\mathrm{CO} / \mathrm{H}_{2}$ stream at $523 \mathrm{~K}$ and only started to segregate below $448 \mathrm{~K}$, as evidenced by a shift of the $\mathrm{CO}$ (ads) band to higher wavenumbers, which are typical of pure Pt [6]. To assess whether or not the observed segregation was only related to temperature

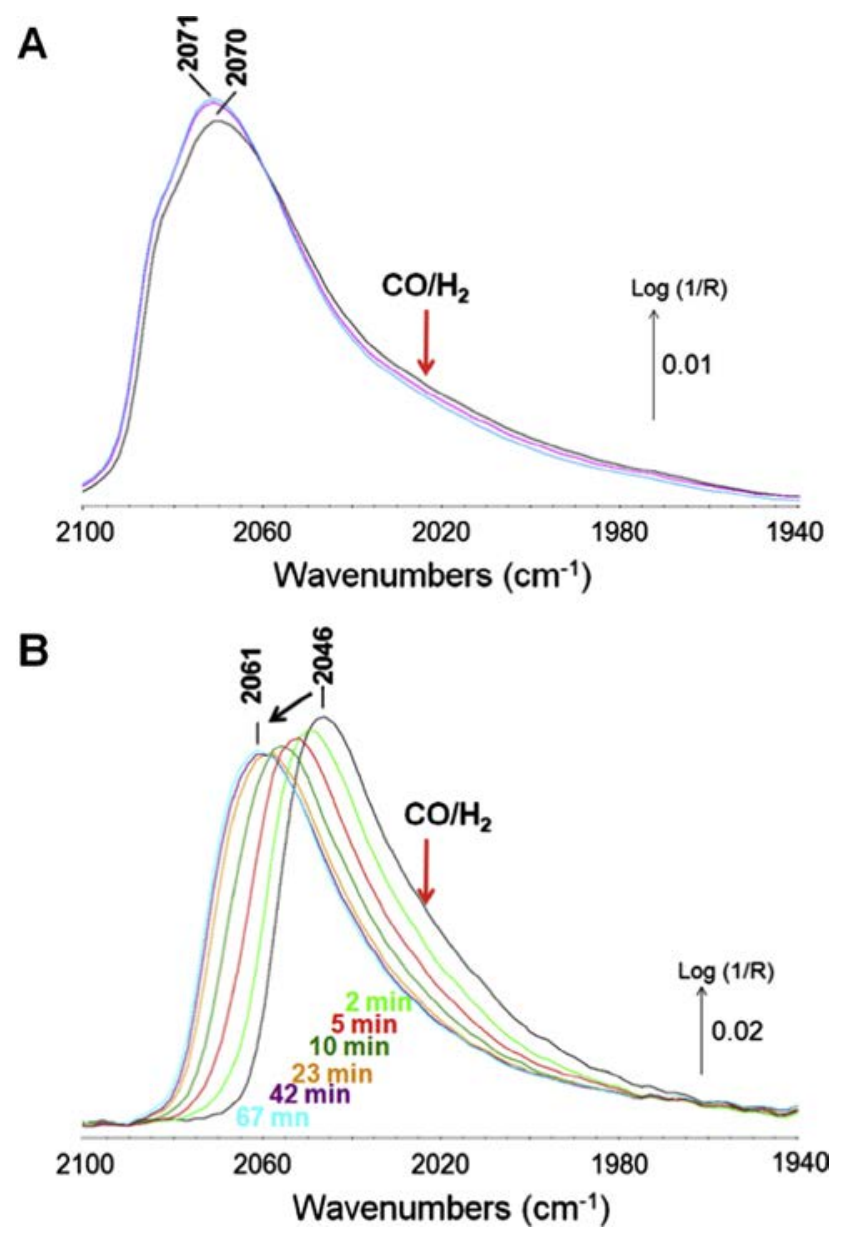

Fig. 1. In situ DRIFTS spectra collected under $2 \% \mathrm{CO} / \mathrm{He}$ at $498 \mathrm{~K}$ over (A) Pt/alumina after 10 (pink) and $30 \mathrm{~min}$ (blue) and (B) Pt-Sn/alumina at 2 (light green), 5 (red), 10 (green), 23 (orange), 42 (purple) and $67 \mathrm{~min}$ (blue). The black spectrum in both figures is the steady-state spectrum collected under $2 \% \mathrm{CO}+10 \% \mathrm{H}_{2}$ in He just before removing $\mathrm{H}_{2}$ from the feed. Total flow was always $50 \mathrm{~mL} \mathrm{~min}{ }^{-1}$. changes, the stability of the alloy was tested isothermally after removing $\mathrm{H}_{2}$ from the feed. Three temperatures were used, 498, 523 and $548 \mathrm{~K}$, all well above the $448 \mathrm{~K}$ threshold. At all these temperatures the $\mathrm{CO}$ (ads) band position shifted to higher wavenumbers following $\mathrm{H}_{2}$ removal (Figs. 1 and $\mathrm{S} 2$ ). This indicates that the Pt-Sn nanoalloy was unstable and segregated once $\mathrm{H}_{2}$ was removed from the feed. The changes were essentially reversible when $\mathrm{H}_{2}$ was brought back, though a slight increase of DRIFTS signal was observed, for instance at $523 \mathrm{~K}$ (Fig. S3), indicating that Pt dispersion was affected to a minor extent by these treatments.

The band shift appeared to be more limited at higher temperature (compare Figs. 1 and S2). The kinetics of this structural modification was followed by plotting the DRIFTS band intensity at $2024 \mathrm{~cm}^{-1}$ (position shown by the red arrow in Fig. 1) as a function of time (Fig. 2). At short times this intensity was mostly representative of the disappearance of the Pt-Sn alloy. The initial segregation rate was taken to be proportional to the slope of the curves at the origin of time (Fig. 2, dotted lines). Interestingly, the segregation rate appeared to decrease with increasing temperatures.

The corresponding Arrhenius-type plot was drawn (Fig. 2, inset), from which a negative apparent activation energy Eapp $=-38 \pm 4 \mathrm{~kJ} \mathrm{~mol}^{-1}$ was calculated. An activation energy of $-35 \pm 4 \mathrm{~kJ} \mathrm{~mol}^{-1}$ was obtained if the segregation process was quantified by following the wavenumber shift of the low wavenumber side of the alloy band at half height (Fig. S4). The two methods used to evaluate the rate of segregation appeared thus consistent.

The fact that both rate and extent of segregation decreased with increasing temperature indicates that the cause of the segregation was kinetically and thermodynamically not favored at higher temperatures. It also indicates that the segregation was a complex process consisting of multiple elementary steps, most likely involving absorption step with a large (negative) heat of adsorption, such as CO sorption on Pt. The CO coverage on Pt atoms of the Pt-Sn phase significantly decreased with temperature over the range of interest, as shown by adsorption isobars measured by DRIFTS (Fig. S5).

If the rate-determining step of the segregation process were the reaction between an adsorbed $\mathrm{CO}$ molecule on platinum and an adjacent surface tin atom, a lower surface coverage of $\mathrm{CO}$ would lead to a lower segregation rate. At low coverages, the apparent

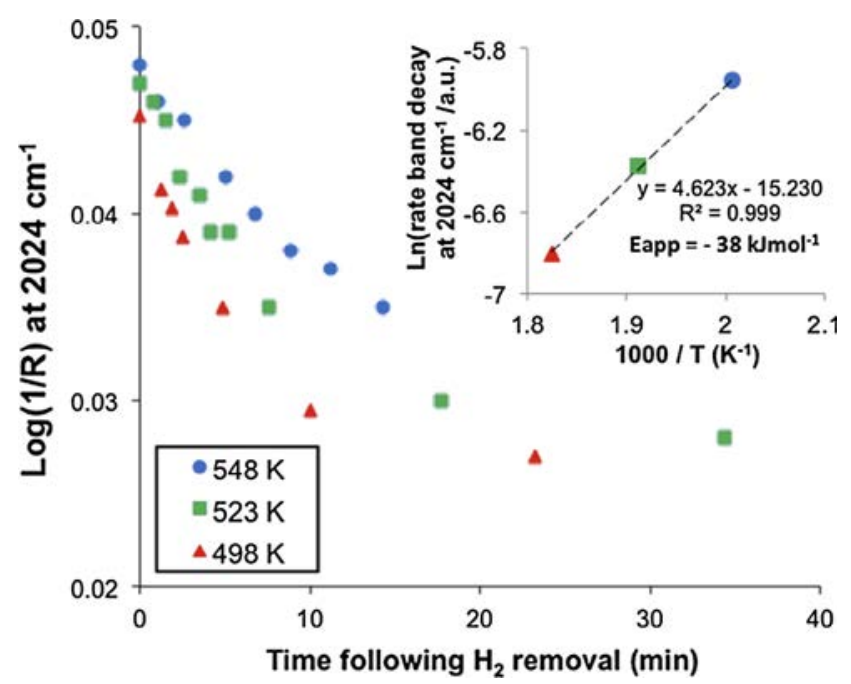

Fig. 2. DRIFTS intensity of the $\mathrm{CO}$ (ads) band at $2024 \mathrm{~cm}^{-1}$ on the $\mathrm{Pt}-\mathrm{Sn} / \mathrm{Al}_{2} \mathrm{O}_{3}$ as a function of time at 498, 523 and $548 \mathrm{~K}$ following the removal of $\mathrm{H}_{2}$ from the feed. Feed: $2 \% \mathrm{CO}$ in He. (Inset) Corresponding Arrhenius-type plots reporting the slopes of the tangent to the curves at the origin of time as a function of the reciprocal temperature. 
activation energy will be the sum of the true activation energy and the $\mathrm{CO}$ heat of adsorption [24]. Knowing that he heat of adsorption of $\mathrm{CO}$ on this Pt-Sn sample at $523 \mathrm{~K}$ is about $-84 \mathrm{~kJ} \mathrm{~mol}^{-1}$ (Fig. S5 and Table S1), a positive true activation energy of ca. $+36 \mathrm{~kJ} \mathrm{~mol}^{-1}$ can be calculated from the apparent activation energy of $-38 \mathrm{~kJ} / \mathrm{mol}$ for the reaction step of adsorbed $\mathrm{CO}$ with a tin surface atom.

Quasi in situ X-ray photoelectron spectroscopy (XPS) was used to determine whether or not the segregation process involved a change in oxidation state for any of the metals initially present in the Pt-Sn alloy. The Pt-Sn/alumina sample was first reduced under a flow of pure hydrogen at $723 \mathrm{~K}$ for $30 \mathrm{~min}$ in a reaction chamber before being transferred into the XPS analysis chamber under ultra-high vacuum (UHV).

The main contribution of the $C 1 \mathrm{~s}$ core level spectrum was used as energy reference at $284.6 \mathrm{eV}$, corresponding to graphite-like $\mathrm{sp}^{2}$ adventitious carbon [25]. This is consistent with the fact that the sample was treated in situ at temperatures sufficiently high to remove $\mathrm{sp}^{3}$ species. The Pt $4 \mathrm{f}$ XPS signal could not be interpreted due to overlapping with $\mathrm{Al} 2 \mathrm{p}$ contribution.

The Sn 3d XPS spectra exhibited the simultaneous presence of metallic (at $484.8 \mathrm{eV}$ ) and oxidized (at $486.6 \mathrm{eV}$ ) tin contributions (Fig. 3A). The atomic percentages of these two tin species are given in Table 1. It is likely that the metallic tin fraction (ca. 62 at.\%) corresponded entirely to tin present in the Pt-Sn alloy nanoparticles, while the remainder (ca. 38 at.\%) corresponded to SnOx species strongly interacting with the alumina. SnOx species strongly bound to the support have been proposed on similar systems $[26,27]$, these species possibly being instrumental in immobilizing supported metal particles [28]. Such species are typically hard to reduce; the tin component of $\mathrm{SnO}_{2}-\mathrm{Al}_{2} \mathrm{O}_{3}$ gels free of noble metals reduces under $\mathrm{H}_{2}$ only above $1073 \mathrm{~K}$ [29].

The same sample was then exposed to a flow of $2 \% \mathrm{CO} / \mathrm{He}$ at $498 \mathrm{~K}$ for $90 \mathrm{~min}$, then evacuated under secondary vacuum and transferred back into the XPS analysis chamber. Surprisingly, tin was more oxidized than before the CO treatment, as the proportion of $\mathrm{Sn}^{0}$ dropped from 62 at.\% down to 31 at.\% (Fig. 3B and Table 1). This result indicates that, surprisingly, $\mathrm{CO}$ had acted as an oxidizer, at least as far as tin was concerned. $\mathrm{CO}$ has already been reported as being able to oxidize $\mathrm{Ag}$ nanoparticles at room temperature, with the concomitant formation of elemental carbon through Boudouard reaction [30].

The $C 1$ s XPS spectrum of the sample reduced at $723 \mathrm{~K}$ exhibited two contributions at high binding energies, beside the main $\mathrm{C}-\mathrm{C}$ $\mathrm{sp}^{2}$ peak at $284.6 \mathrm{eV}$ used as a reference (Fig. 3C). The peak at $286.8 \mathrm{eV}$ corresponded to CO linearly adsorbed on Pt [31,32] and that at $289.2 \mathrm{eV}$ could be attributed to the formation of COx-type groups such as carbonates and carboxylates [25].

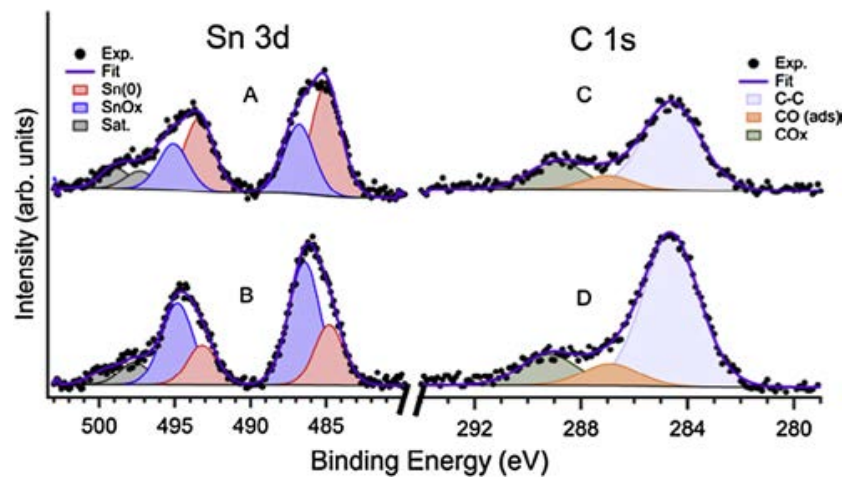

Fig. 3. (A) Sn 3d and (C) C 1s XPS spectrum of Pt-Sn/alumina after reduction under hydrogen at $723 \mathrm{~K}$. (B) and (D) Same analyses on the same sample that had been subsequently exposed for $90 \mathrm{~min}$ at $498 \mathrm{~K}$ to $2 \% \mathrm{CO} / \mathrm{He}$.
Table 1

$\mathrm{X}$-ray photoelectron spectroscopy binding energies of various Sn and C species and the corresponding atomic percentages.

\begin{tabular}{llll}
\hline $\begin{array}{l}\text { Sn or C } \\
\text { compound }\end{array}$ & $\begin{array}{l}\text { Binding } \\
\text { energy }(\mathrm{eV})\end{array}$ & $\begin{array}{l}\text { Atomic \% after } \\
\mathrm{H}_{2} \text { at } 723 \mathrm{~K}\end{array}$ & $\begin{array}{l}\text { Atomic \% after } \\
\text { CO at } 498 \mathrm{~K}\end{array}$ \\
\hline $\mathrm{Sn}^{\circ}$ & 484.8 & 62 & 31 \\
$\mathrm{SnOx}$ & 486.6 & 38 & 69 \\
$\mathrm{C}-\mathrm{C} \mathrm{sp}{ }^{2}$ & 284.6 & 70 & 78 \\
$\mathrm{CO}($ ads $)$ & 286.8 & 5 & 9 \\
$\mathrm{COx}$ & 289.2 & 25 & 13 \\
\hline
\end{tabular}

The evolution of the XPS C 1s signal following exposure to $2 \%$ $\mathrm{CO} / \mathrm{He}$ at $498 \mathrm{~K}$ was quite remarkable (Fig. 3D and Table 1). A marked increase in the proportion of $\mathrm{C}-\mathrm{C} \mathrm{sp}^{2}$ bond typical of graphitic carbon was observed, alongside the expected increase of the signal associated with $\mathrm{CO}(\mathrm{ads})$. In contrast, the band associated with more oxidized COx species decreased. These observations suggest that $\mathrm{CO}$ reacted through a direct decomposition to yield graphitic elemental carbon and oxygen (Eq. (1)) rather than through Boudouard reaction (Eq. (2)):

$\mathrm{CO}($ ads $) \rightarrow \mathrm{C}($ ads $)+\mathrm{O}($ ads $)$

$2 \mathrm{CO}($ ads $) \rightarrow \mathrm{C}($ ads $)+\mathrm{CO}_{2}$

The oxygen formed could subsequently have reacted with the Sn present in the alloy, explaining the increased fraction of oxidized tin following exposure to $\mathrm{CO}$ (Table 1). The conversion of $\mathrm{CO}$ in the absence of $\mathrm{H}_{2}$ was investigated over the Pt and Pt-Sn/ alumina materials (Fig. S6). The production of $\mathrm{CO}_{2}$ was found to be negligible below $573 \mathrm{~K}$, supporting our earlier observation that Boudouard reaction (Eq. (2)) is negligible at lower temperatures over these materials.

The chemical state of $\mathrm{Sn}$ in the Pt-Sn/alumina and the effect of the feed composition at $498 \mathrm{~K}$ were investigated by in situ X-ray Absorption Spectroscopy (XAS). The details and sequence of the XAS measurements are given as Supporting Information. Fig. 4 presents the XANES data at the Sn K-edge. The overall edge shifts to higher energies and the increase in the white line intensity of the

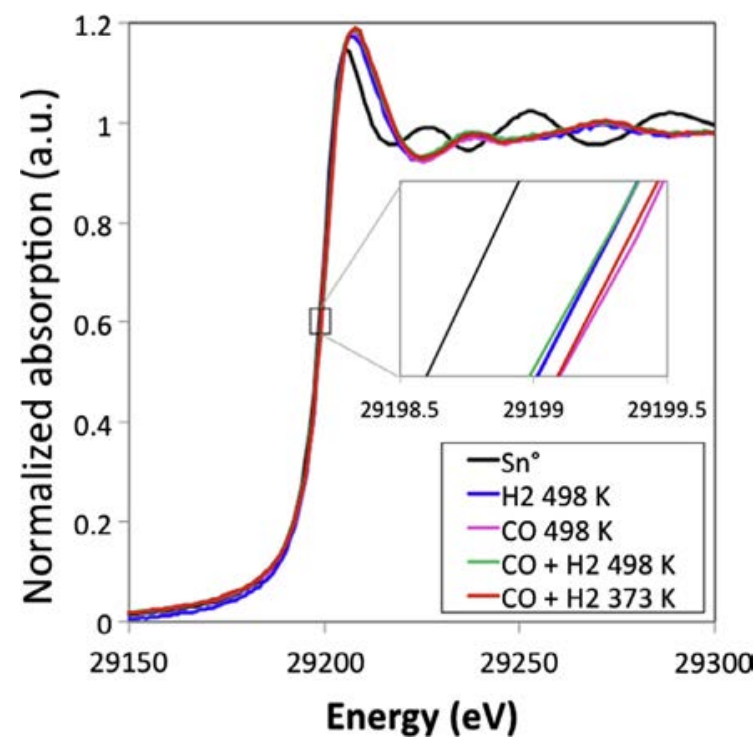

Fig. 4. Normalized Sn K-edge XANES spectra of the Pt-Sn/alumina sample exposed to different atmospheres and spectrum of a $\mathrm{Sn}^{0}$ standard. The inset zooms in the edge position, highlighting a shift towards higher energies of the white line position when the sample was exposed to $2 \% \mathrm{CO}+60 \% \mathrm{H}_{2}$ at $373 \mathrm{~K}$ or only $2 \% \mathrm{CO}$ at $\mathrm{T}=498$ $\mathrm{K}$. He was used as diluent. 
alloy-related spectra as compared to those of the metallic Sn ${ }^{\circ}$ reference (black line) could be mainly due to two effects. First, alloying Sn with Pt induces a transfer of electrons from Sn towards the more electronegative Pt causing a partial filling of the Pt $\mathrm{d}$ band vacancies [33]. Second, oxidized Sn species strongly interacting with the alumina may be present, even after the reduction in $\mathrm{H}_{2}$ at $723 \mathrm{~K}$, as already indicated by the XPS analysis (Fig. 3).

The modification of the Sn K-edge XANES spectra of the Pt-Sn/ alumina under various feed compositions were relatively limited but could still be resolved (inset of Fig. 4). The edge clearly shifted to higher energies under $2 \% \mathrm{CO} / \mathrm{He}$ (pink line) as compared to $60 \%$ $\mathrm{H}_{2} / \mathrm{He}$ (blue line), indicating a more oxidized state of $\mathrm{Sn}$ in the presence of $\mathrm{CO}$. The edge shifted back to lower energies to the state equivalent to that obtained under $60 \% \mathrm{H}_{2} / \mathrm{He}$ when exposed to $2 \%$ $\mathrm{CO}+60 \% \mathrm{H}_{2}$ (green line). However, $\mathrm{Sn}$ became again more oxidized once temperature was dropped to $373 \mathrm{~K}$ (red line), still under $2 \%$ $\mathrm{CO}+60 \% \mathrm{H}_{2}$.

These XANES Sn K-edge data are consistent with the interpretation of the in situ DRIFTS data reported above. Pt-Sn alloy nanoparticles were present at $498 \mathrm{~K}$ under $\mathrm{CO}+\mathrm{H}_{2}$, associated with $\mathrm{CO}$ (ads) DRIFTS bands at ca. $2046 \mathrm{~cm}^{-1}$ (Fig. 1). The Pt-Sn phase segregated when no $\mathrm{H}_{2}$ was present, leading to a metallic Pt-rich phase associated with a $\mathrm{CO}$ (ads) band at $2061 \mathrm{~cm}^{-1}$. Importantly, the XANES Sn K-edge data indicate that Sn gets oxidized during this process and thus supports the conclusions obtained from the XPS data (Fig. 3) that exposure to $\mathrm{H}_{2}$-free $\mathrm{CO}$ does indeed lead to the oxidation of tin at $498 \mathrm{~K}$.

The XANES analysis (Fig. 4, red line) highlights a similar Pt-Sn segregation involving Sn oxidation when temperature is decreased to $373 \mathrm{~K}$, consistent with earlier observations derived from in situ DRIFTS data that segregation was triggered even in the presence of $\mathrm{H}_{2}$ when temperature was decreased below $448 \mathrm{~K}^{6}$.

Pt L3-edge XANES data only revealed the presence of metallic Pt under all conditions (Fig. S7 and XANES and EXAFS Analyses in the Supporting Information). White line increase and shift were observed upon adsorption of $\mathrm{CO}$, which overall withdrew electronic density from Pt. The Pt-CO bonding involves the filled $5 \sigma$ (HOMO) and empty $2 \pi^{*}$ (antibonding LUMO) orbitals of CO overlapping with Pt $5 \mathrm{~d}$ orbitals. The HOMO of $\mathrm{CO}$ donates electron to $\mathrm{Pt}$, while the LUMO of $\mathrm{CO}$ accepts electron from Pt, the later transfer being dominant. The weaker heat of adsorption of CO (Fig. S5 and Table S1) measured on Pt-Sn phases, which exhibit an electron-richer Pt as compared to the case of pure Pt particles, indicates that the additional electronic density supplied by Sn to Pt decreased the bond strength between Pt and CO. This indicates that the sigma donation from CO to Pt was more decreased (because the $\mathrm{Pt}$ becomes less acceptor) than the donation from Pt to CO LUMO was increased.

The EXAFS data collected at the corresponding Pt and Sn edges both indicated the presence of alloy nanoparticles on the reduced sample (Figs. S8-S11 and Table S2). However, the precision of the EXAFS data could not clearly evidence phase segregation in the presence of CO only. This may be due to the disorder and compositional variations in the Pt-Sn particles, in addition to variations in particle size (Fig. S1).

Overall, the combination of DRIFTS, XPS and XANES Sn K-edge data clearly indicates that the present mode of alloy segregation involved the oxidation of some of the tin initially present in the alloyed nanoparticles.

It is important to note that the segregation process was essentially reversed simply by exposing the sample to a $\mathrm{H}_{2}$ or $\mathrm{CO} / \mathrm{H}_{2}$-containing feed at temperature above ca. $448 \mathrm{~K}$ (Fig. S3). An in situ DRIFTS experiment realized over a sample initially segregated at $323 \mathrm{~K}$ showed that the pure Pt domains were gradually converted back into Pt-Sn domains as the temperature was increased (Fig. 5). These spectra show clearly resolved bands of

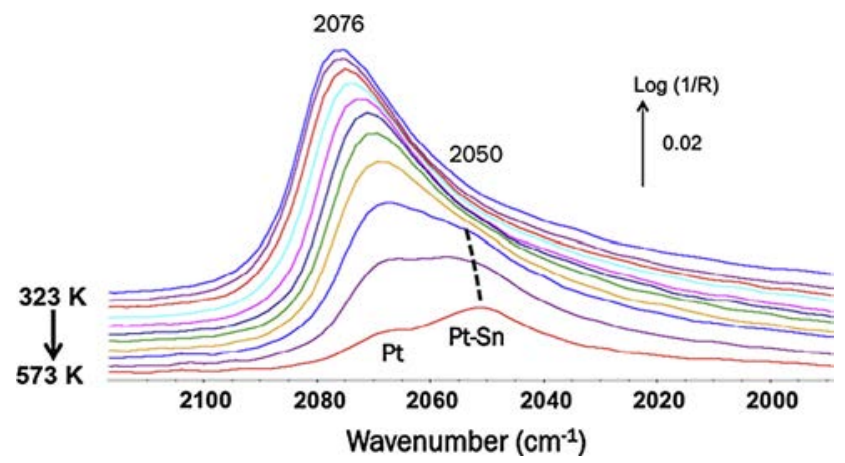

Fig. 5. In situ DRIFTS spectra collected under $2 \% \mathrm{CO}+10 \% \mathrm{H} 2$ in He over Pt-Sn/ alumina during a temperature program from 323 up to $573 \mathrm{~K}$ using a ramp of $10 \mathrm{~K}$ $\mathrm{min}^{-1}$. Spectra are reported every $25 \mathrm{~K}$. The sample was initially reduced at $673 \mathrm{~K}$ under $\mathrm{H} 2$, before being fully segregated under the full stream at $323 \mathrm{~K}$ for $2 \mathrm{~h}$. Total

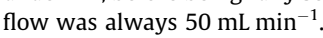

CO either adsorbed on Pt (bands at $2076-2066 \mathrm{~cm}^{-1}$ ) or Pt-Sn (ca. $2050 \mathrm{~cm}^{-1}$ ) during the temperature program (Fig. 5). (The lower signal intensity at higher temperature is merely due to temperature-dependent surface coverage of CO, see Fig. S5).

The possibility that the segregation was triggered by contaminant traces of $\mathrm{O}_{2}$ in the present cases was carefully considered. A concentration of $2 \mathrm{vol} \%$ of $\mathrm{O}_{2}$ was shown to readily segregates the alloy phase [16], even in the presence of $\mathrm{CO}$ and $\mathrm{H}_{2}$ at $498 \mathrm{~K}$. Additional experiments were carried out with the addition of significantly lower $\mathrm{O}_{2}$ concentration (i.e. $100 \mathrm{ppm}$ ) that led to a fast band shift from 2050 to $2064 \mathrm{~cm}^{-1}$ (Fig. S12). The far slower segregation rate observed in previous experiments realized on different setups (DRIFTS cell, XPS setup, synchrotron setup) would therefore have to be related to far lower concentrations of $\mathrm{O}_{2}$.

Potential leakage of ambient air into our DRIFTS cell was considered. In fact, hydrogenation reactions at low temperatures have been routinely performed over Ni-based catalysts, which are highly oxygen-sensitive. Toluene hydrogenation at $70{ }^{\circ} \mathrm{C}$ over Ni nanoparticles embedded in a zeolite (sample preparation reported elsewhere [34]) led a fast irreversible deactivation when $300 \mathrm{ppm}$ of $\mathrm{O}_{2}$ was introduced (Fig. S13). In contrast, the deactivation rate was close to zero when no $\mathrm{O}_{2}$ was added to the feed (Fig. S13). The minute apparent deactivation rate, if truly significant and due to $\mathrm{O}_{2}$, would lead to an $\mathrm{O}_{2}$ concentration of about $1.1 \mathrm{ppm}$ (note that other causes of deactivation could also be expected in this case, Ni sintering, surface reconstruction and carbonaceous deposits). In conclusion, our DRIFTS cell can be considered as essentially leak-free.

The data reported in Fig. S6 showed that no $\mathrm{CO}_{2}$ could be observed as long as Boudouard reaction had not become relevant, indicating that $\mathrm{CO}_{2}$ level was below $10 \mathrm{ppm}$ (analysis threshold) for these reactions carried out under $15.8 \% \mathrm{CO} / \mathrm{He}$. The corresponding $\mathrm{O}_{2}$ contamination level in our typical $2 \% \mathrm{CO} / \mathrm{H}_{2}$ feed would then be less than $1 \mathrm{ppm}$.

The additional graphite-like carbon build-up observed under XPS conditions (Fig. 3 and Table 1) is a further support for the CO-induced oxidation, likely involving direct CO dissociation (Eq. (1)) rather than Boudouard reaction (Eq. (2)). Instead, an increased presence of $\mathrm{COx}$ species would have been expected if the oxidation were due to the occurrence of Boudouard reaction, or even $\mathrm{O}_{2}$ traces, and this was clearly not the case. Furthermore, the negative activation energy measured for the segregation process (Fig. 2) fits well with $\mathrm{CO}$ adsorption on platinum, which is reversible at these temperatures, but not with $\mathrm{O}_{2}$ adsorption. Increasing the temperature from 498 to $548 \mathrm{~K}$ would not lead to a lower oxygen surface concentration, as oxygen does not desorb from Pt nanoparticles significantly at these temperatures [35]. An increase in the 


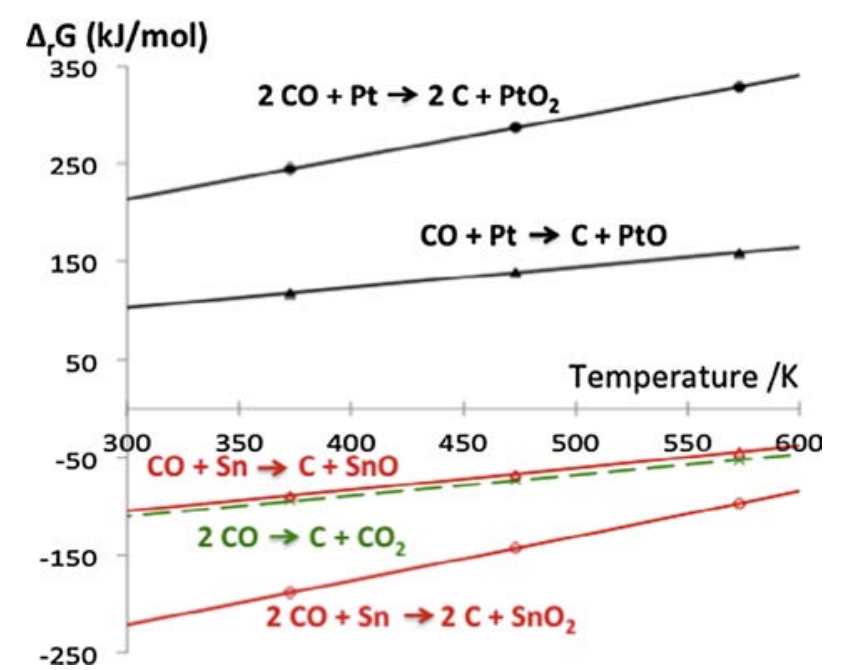

Fig. 6. Gibbs energy of reaction associated with the oxidation of bulk Pt and Sn by $\mathrm{CO}$ and the concomitant formation of carbon. The curves were calculated for a partial pressure of $\mathrm{CO}$ of $2 \mathrm{kPa}$.

segregation rate with increasing temperature would thus be expected if $\mathrm{O}_{2}$ were involved, while the opposite was observed experimentally (Fig. 2).

Based on the DRIFTS, XPS and XANES results we can conclude that the segregation of Pt-Sn by CO occurred via the oxidation of Sn only, since the state of Pt appeared to remain metallic (Figs. 1 and S7). The thermodynamics of the oxidation by $\mathrm{CO}$ of bulk Pt and Sn supported this observation. The Gibbs energy of the oxidation of $\mathrm{Sn}$ by $\mathrm{CO}$ to $\mathrm{SnO}$ or $\mathrm{SnO}_{2}$, with the concomitant formation of carbon, was always negative up to $773 \mathrm{~K}$ (Fig. 6).

In contrast, the equilibria involving $\mathrm{Pt}$ were always unfavourable over this temperature range. These findings, although corresponding to bulk phases, provide a rational for the reactivity and segregation of our Pt-Sn nanoparticles. The oxidation of metallic silver by $\mathrm{CO}$ and concomitant carbon deposition was already proposed by Bechoux et al. based on in situ IR analyses [30].

On a kinetic point of view, platinum is a poor catalyst for $\mathrm{CO}$ dissociation. Somorjai and co-workers have yet shown that Pt steps could dissociate $\mathrm{CO}$ at room temperature [36] and also on $\mathrm{Pt}\left(\begin{array}{lll}1 & 0 & 0\end{array}\right)$ at $498 \mathrm{~K}$ [37]. The kinetics of dissociation on pure Pt phases may not be favored by the fact that each Pt site is likely to be covered and strongly poisoned by CO. In contrast, the CO-free Sn of Pt-Sn surfaces may provide a more favourable path for the dissociation of $\mathrm{CO}$ with subsequent adsorption of the formed oxygen on the oxophilic Sn. The exclusion of CO adsorption on the Sn sites was also suggested by Wang and Hsing as one of the reasons for the improved electrocatalytic performance of Pt-Sn electrodes for CO oxidation [20].

The roles of temperature and $\mathrm{H}_{2}$ on the occurrence and rate of segregation (resp. re-alloying) likely relate to the formation (resp. removal) of $\mathrm{O}$ (ads) formed from $\mathrm{CO}$ dissociation. If no hydrogen is present or if the temperature is too low to enable water formation from the reaction between $\mathrm{H}_{2}$ and $\mathrm{O}$ (ads), then $\mathrm{O}$ (ads) will react with the Sn component of the alloy leading to segregation (Fig. 1). If $\mathrm{H}_{2}$ is brought back and the temperature is high enough, the reduction of SnOx occurs and the Pt-Sn alloy will be restored (Figs. 4, 5 and S3).

\section{Conclusion}

In summary, we unravel here for the first time a new mode of segregation of Pt-Sn alloy nanoparticles occurring as a consequence of the dissociation of $\mathrm{CO}$ leading to Sn oxidation and carbon deposition. This segregation mode is favored at low temperatures (ca. $<448 \mathrm{~K}$ ) and in the absence of $\mathrm{H}_{2}$. In effect, $\mathrm{CO}$ acts as an oxidising agent, with concomitant deposition of carbon. The process is yet reversible. While a contamination by traces of $\mathrm{O}_{2}$ at the subppm level cannot be excluded, the data reported indicate that the structural modifications undergone by the Pt-Sn nanoparticles are more consistent with a reaction involving $\mathrm{CO}$ rather than one involving $\mathrm{O}_{2}$. In particular, the XPS analysis after $\mathrm{CO}$ exposure revealed an increased fraction of graphitic carbon, while that of oxidized carbon decreased. Thermodynamic calculations indicate that the oxidation of tin by $\mathrm{CO}$, with concomitant carbon formation $(\mathrm{Sn}+\mathrm{CO} \rightarrow \mathrm{SnO}+\mathrm{C})$ is as favourable as Boudouard reaction (2 CO $\rightarrow \mathrm{CO} 2+\mathrm{C}$ ) at low temperatures. It would be of paramount interest to investigate the relevance of this process during the operation of other alloy-based electrodes used for $\mathrm{H}_{2}$ oxidation, in which $\mathrm{CO}$ traces can be present at low temperatures, and may lead to the oxidation of the most oxophilic metal of the alloy.

\section{Experimental Section}

\subsection{Materials and gases}

Pt-containing mono and bimetallic supported catalysts were synthesized using a two-step methodology. Pt and Pt-Sn nanoparticles (NPs) were first prepared using a colloidal method. A mixture of a Pt complex [i.e. $\mathrm{Pt}(\mathrm{dba})_{2}(\mathrm{dba}=$ dibenzylidene acetone)] and octylsilane, which acted as a ligand, was used for the synthesis of Pt monometallic NPs. Pt-Sn NPs were obtained by contacting Pt $(\mathrm{dba})_{2}$ and tributyltin hydride $\left[(\mathrm{n}-\mathrm{Bu})_{3} \mathrm{SnH}\right]$ without the addition of any other ligand [21]. The precursors were dissolved in dry tetrahydrofuran (THF) and pressurized with $\mathrm{H}_{2}$ (3 bar) during 10 $\mathrm{h}$ at room temperature. The colloidal suspension was further used for the second step of the catalyst preparation. Following the evaporation of the solvent, a small volume of the suspension was added to the $\gamma-\mathrm{Al}_{2} \mathrm{O}_{3}$ support (BET surface area of $106 \mathrm{~m}^{2} / \mathrm{g}$ ) under continuous stirring and non-oxidative atmosphere and then dried overnight under Ar. The dry crude catalysts were subsequently calcined under flowing dry air at $593 \mathrm{~K}$ in order to remove most of the alkyl fragments. High purity $\mathrm{He}$ and $\mathrm{H}_{2}$ from Air Liquide (Alphagaz, 99.999\% purity) further purified with using $\mathrm{VICI}^{\circledR}$ traps (models P100-2 and P-200-2 for He and $\mathrm{H}_{2}$, respectively) were used, which should have brought down $\mathrm{O}_{2}$ level below $1 \mathrm{ppm}$. High purity $\mathrm{CO}$ (>99\%, main impurity $\mathrm{N}_{2} \sim 0.4 \mathrm{~mol} . \%$ and $\mathrm{H}_{2} \sim 0.5 \mathrm{~mol} . \%$ ) was used without further purification.

\subsection{Diffuse reflectance FT-IR}

DRIFTS experiments were performed at ambient pressure with a high temperature DRIFT cell (from Spectra-Tech ${ }^{\circledR}$ ) fitted with $\mathrm{KBr}$ windows, using a collector assembly. A description and properties of the cell can be found elsewhere [38]. The spectrophotometer used was a Nicolet 6700 (ThermoFischer Scientific) fitted with a liquid- $\mathrm{N}_{2}$ cooled MCT detector. The DRIFT spectra were recorded at a resolution of $4 \mathrm{~cm}^{-1}$ and 8 or 32 scans accumulation depending on the time-resolution desired. The DRIFTS spectra are reported as $\log (1 / R)$, where $R$ is the sample reflectance. This pseudoabsorbance gives a better linear representation of the band intensity against surface coverage than that given by the Kubelka-Munk function for strongly absorbing media such as those based on metals supported on oxides [39]. The contribution of gas-phase CO was subtracted using a $\mathrm{CO}(\mathrm{g})$ spectrum collected at the reaction temperature over a SiC powder [40].

\subsection{X-ray absorption spectroscopy}

Scheme S1 shows the treatment applied to the catalysts during the XAS experiments at the Pt- $\mathrm{L}_{3}$ and Sn-K edges. The catalysts 
were initially reduced under $30 \% \mathrm{H}_{2} / \mathrm{He}$ up to $673 \mathrm{~K}(10 \mathrm{~K} / \mathrm{min})$ and maintained at this temperature for $40 \mathrm{~min}$. The temperature was then decreased to $498 \mathrm{~K}$ where the EXAFS spectra were collected (I). The atmosphere was then switched to $2 \% \mathrm{CO} / 60 \% \mathrm{H}_{2} / \mathrm{He}$ and EXAFS spectra were collected at the Pt-edge (II). $\mathrm{H}_{2}$ was subsequently removed from the feed (balanced by He to keep the same total flow) and EXAFS spectra were measured (III) at both edges. Finally, $\mathrm{H}_{2}$ was added back to the feed and the last EXAFS spectra at $498 \mathrm{~K}$ were collected (IV). For the final data collection at the Sn-edge, the atmosphere was changed to $30 \% \mathrm{H}_{2} / \mathrm{He}$ and the temperature was ramped up until $673 \mathrm{~K}(10 \mathrm{~K} / \mathrm{min})$. After $40 \mathrm{~min}$, the temperature was decreased to $373 \mathrm{~K}$ where another EXAFS spectra was collected $(\mathrm{V})$. A stabilization period of $30 \mathrm{~min}$ was used before the EXAFS measurements each time conditions were changed. Three EXAFS spectra were collected and averaged for data analysis.

\section{Acknowledgements}

A.M. acknowledges the PhD scholarship from the Ministry of higher Education and Research of France at the University of Lyon. Prof Xenophon Verykios from Patras University is acknowledged for organizing the student exchange of C.T. The authors thank Laurent Veyre for the TEM analyses and Pascale Mascunan for ICP measurements. The European Synchrotron Radiation Facility (ESRF) is acknowledged for the allocated beamtime (IHCH973).

\section{References}

[1] B. Huang, H. Kobayashi, T. Yamamoto, S. Matsumura, Y. Nishida, K. Sato, K. Nagaoka, S. Kawaguchi, Y. Kubota, H. Kitagawa, Solid-solution alloying of immiscible Ru and $\mathrm{Cu}$ with enhanced CO oxidation activity, J. Am. Chem. Soc. 139 (2017) 4643-4646.

[2] S. Zafeiratos, S. Piccinin, D. Teschner, Alloys in catalysis: phase separation and surface segregation phenomena in response to the reactive environment, Catal. Sci. Technol. 2 (2012) 1787-1801.

[3] F. Besenbacher, I. Chorkendorff, B.S. Clausen, B. Hammer, A.M. Molenbroek, J.K. Norskov, I. Stensgaard, Design of a surface alloy catalyst for steam reforming, Science 279 (1998) 1913-1915.

[4] A. Virnovskaia, S. Morandi, E. Rytter, G. Ghiotti, U. Olsbye, Characterization of $\mathrm{Pt}, \quad \mathrm{Sn} / \mathrm{Mg}(\mathrm{Al}) \mathrm{O}$ catalysts for light alkane dehydrogenation by FT-ir spectroscopy and catalytic measurements, J. Phys. Chem. C 111 (2007) $14732-14742$

[5] Z. Liu, G.S. Jackson, B.W. Eichhorn, PtSn intermetallic, core-shell, and alloy nanoparticles as CO-tolerant electrocatalysts for $\mathrm{H} 2$ oxidation, Ang. Chem. Int Ed. 49 (2010) 3173-3176.

[6] A. Moscu, Y. Schuurman, L. Veyre, C. Thieuleux, F. Meunier, Direct evidence by in situ IR CO monitoring of the formation and the surface segregation of a PtSn alloy, Chem. Commun. 50 (2014) 8590-8592.

[7] P. He, L.B. Zhang, D.S. He, G. Zhou, Y. Lin, Z.X. Deng, X. Hong, Y. Wu, C. Chen, Y. D. Li, Amorphous nickel boride membrane on a platinum-nickel alloy surface for enhanced oxygen reduction reaction, Nat. Commun. 7 (2016) 12362.

[8] M.F. Chi, C. Wang, Y.K. Lei, G.F. Wang, D.G. Li, K.L. More, A. Lupini, L.F. Allard, N. M. Markovic, V.R. Stamenkovic, Surface faceting and elemental diffusion behavior at atomic scale for alloy nanoparticles during in situ annealing, Nat. Commun. 6 (2015) 9925.

[9] J.J. Mayrhofer, V. Juhart, K. Hartl, M. Hanzlik, M. Arenz, Adsorbate-induced surface segregation for core-shell nanocatalysts, Angew. Chem. Int. Ed. 48 (2009) 3529-3531.

[10] M. Lopez-Haro, L. Dubau, L. Guétaz, P. Bayle-Guillemaud, M. Chatenet, J. André, N. Caqué, E. Rossinot, F. Maillard, Atomic-scale structure and composition of Pt3Co/C nanocrystallitesduring real PEMFC operation: a STEM-EELS study, Appl. Catal. B: Env. (2014) 300-308.

[11] Y.C. Hsieh, Y. Zhang, D. Su, V. Volkov, R. Si, L.J. Wu, Y.M. Zhu, W. An, P. Liu, P. He, S. Ye, R.R. Adzic, J.X. Wang, Ordered bilayer ruthenium-platinum core shell nanoparticles as carbon monoxide-tolerant fuel cell catalysts, Nat. Commun. 4 (2013) 2466.

[12] C.H. Cui, L. Gan, M. Neumann, M. Heggen, B.R. Cuenya, P. Strasser, Solidsolution alloying of immiscible $\mathrm{Ru}$ and $\mathrm{Cu}$ with enhanced $\mathrm{CO}$ oxidation activity, J. Am. Chem. Soc. 136 (2014) 4813-4816.
[13] L.L. Han, Q.P. Meng, D.L. Wang, Y.M. Zhu, J. Wang, W. Du, E.A. Stach, H.L. Xin, Interrogation of bimetallic particle oxidation in three dimensions at the nanoscale, Nat. Comm. 7 (2016) 13335.

[14] L. Delannoy, S. Giorgio, J.G. Mattei, C.R. Henry, N. El Kolli, C. Methievier, C. Louis, Surface segregation of Pd from TiO2-supported AuPd nanoalloys under CO oxidation conditions observed Insitu by ETEM and DRIFTS, ChemCatChem 5 (2013) 2707-2716

[15] W.D. Michalak, J.M. Krier, S. Alayoglu, J.Y. Shin, K. An, K. Komvopoulos, Z. Liu, G.A. Somorjai, CO oxidation on PtSn nanoparticle catalysts occurs at the interface of Pt and Sn oxide domains formed under reaction conditions, J. Catal. 312 (2014) 17-25.

[16] A. Moscu, L. Veyre, C. Thieuleux, F. Meunier, Y. Schuurman, CO PROX over PtSn/Al203: a combined kinetic and in situ DRIFTS study, Catal. Today 258 (2015) 241-246.

[17] M.S. Kumar, D. Chen, A. Holmen, J.C. Walmsley, Dehydrogenation of propane over Pt-SBA-15 and Pt-Sn-SBA-15: effect of Sn on the dispersion of Pt and catalytic behavior, Catal. Today 142 (2009) 17-23.

[18] J.J.H.B. Sattler, A.M. Beale, B.M. Weckhuysen, Operando Raman spectroscopy study on the deactivation of Pt/Al2O3 and Pt-Sn/Al2O3 propane dehydrogenation catalysts, Phys. Chem. Chem. Phys. 15 (2013) 12095-12103.

[19] Y.J. Leng, X. Wang, I.M. Hsing, Assessment of CO-tolerance for different Pt-alloy anode catalysts in a polymer electrolyte fuel cell using ac impedance spectroscopy, J. Electroanal. Chem. 528 (2002) 145-152.

[20] X. Wang, I.M. Hsing, Kinetics investigation of $\mathrm{H}-2 / \mathrm{CO}$ electro-oxidation on carbon supported $\mathrm{Pt}$ and its alloys using impedance based models, J. Electroanal. Chem. 556 (2003) 117-126.

[21] M. Boualleg, D. Baudouin, J.-M. Basset, F. Bayard, J.-P. Candy, J.-C. Jumas, L. Veyre, C. Thieuleux, Unexpected, spontaneous and selective formation of colloidal Pt3Sn nanoparticles using organometallic Pt and Sn complexes, Chem. Commun. 46 (2010) 4722-4724.

[22] A. Moscu, Y. Schuurman, L. Veyre, C. Thieuleux, F. Meunier, Direct evidence by in situ IR CO monitoring of the formation and the surface segregation of a PtSn alloy, Chem. Commun. 50 (2014) 8590-8592.

[23] P. Liu, A. Logadottir, J.K. Nørskov, Modeling the electro-oxidation of CO and H2/ CO on Pt, Ru, PtRu and Pt3Sn, Electroch. Acta 48 (2003) 3731-3742.

[24] G.C. Bond, Kinetics of alkane reactions on metal catalysts: activation energies and the compensation effect, Catal. Today 49 (1999) 41-48.

[25] D.J. Miller, M.C. Biesinger, N.S. McIntyre, Interactions of $\mathrm{CO} 2$ and $\mathrm{CO}$ at fractional atmosphere pressures with iron and iron oxide surfaces: one possible mechanism for surface contamination?, Surf Interf. Anal. 33 (2002) 299-305.

[26] M. Womes, F. Le Peltier, S. Morin, B. Didillon, J. Olivier-Fourcade, J.C. Jumas, Study of the reaction mechanisms between $\mathrm{Sn}-(\mathrm{n}-\mathrm{C}(4) \mathrm{H}(9))(4)$ and alumina surface sites - application to the controlled preparation of $\mathrm{PtSn} / \mathrm{Al}(2) \mathrm{O}(3)$ catalysts, J. Mol. Catal. A: Chem. 266 (2007) 55-64.

[27] S.R. Adkins, B.H. Davis, The chemical-state of tin in platinum tin alumina catalysts, J. Catal. 89 (1984) 371-379.

[28] H.N. Pham, J.J.H.B. Sattler, B.M. Weckhuysen, A.K. Datye, Role of Sn in the regeneration of Pt/gamma-Al2O3 light alkane dehydrogenation catalysts, ACS Catal. 6 (2016) 2257-2264.

[29] P. Kirszensztejn, A. Tolinska, R. Przekop, Thermal analysis of gel-derived support for metallic catalysts Part II. Al2O3-SnO2 system in reductive atmosphere, J. Therm. Anal. Calorim. 95 (2009) 93-98.

[30] K. Bechoux, O. Marie, M. Daturi, G. Delahay, C. Petitto, S. Rousseau, G. Blanchard, Infrared evidence of room temperature dissociative adsorption of carbon monoxide over Ag/Al203, Catal. Today 197 (2012) 155-161.

[31] O. Bjorneholm, A. Nilsson, H. Tillborg, P. Bennich, A. Sandell, B. Hernnas, C. Puglia, N. Martensson, Overlayer structure from adsorbate and substrate corelevel binding energy shifts - CO, CCH3 AND O on Pt(111), Surf. Sci. 315 (1994) L983-L989.

[32] B. Trankenschuh, C. Papp, T. Fuhrmann, R. Denecke, H.-P. Steinruck, Kinetic isotope effects and reaction intermediates in the decomposition of methyl on flat and stepped platinum (111) surfaces, Surf. Sci. 601 (2007) 1108-1117.

[33] S. Mukerjee, J. McBreen, An in situ X-ray absorption spectroscopy investigation of the effect of $\mathrm{Sn}$ additions to carbon-supported Pt electrocatalysts - Part I, J. Electrochem. Soc. 146 (1999) 600-606.

[34] D. Laprune, A. Tuel, D. Farrusseng, F.C. Meunier, ChemCatChem 9 (2017) $2297-$ 2307.

[35] E.S. Putna, J.M. Vohs, R.J. Gorte, Oxygen desorption from alpha-Al203(0001) supported Rh, Pt and Pd particles, Surf. Sci. 391 (1997) L1178-L1182.

[36] Y. Iwasawa, R. Mason, M. Textor, G.A. Somorjai, Reactions of carbon monoxide at coordinatively unsaturated sites on a platinum surface, Chem. Phys. Lett. 44 (1976) 468-470.

[37] K.R. McCrea, J.S. Parker, G.A. Somorjai, The role of carbon deposition from CO dissociation on platinum crystal surfaces during catalytic CO oxidation: effects on turnover rate, ignition temperature, and vibrational spectra, J. Phys. Chem. B 106 (2002) 10854-10863.

[38] H. Li, M. Rivallan, F. Thibault-Starzyk, A. Travert, F.C. Meunier, Effective bulk and surface temperatures of the catalyst bed of FT-IR cells used for in situ and operando studies, Phys. Chem. Chem. Phys. 15 (2013) 7321-7327.

[39] J. Sirita, S. Phanichphant, F.C. Meunier, Quantitative analysis of adsorbate concentrations by diffuse reflectance FT-IR, Anal. Chem. 79 (2007) 3912-3918.

[40] A. Paredes-Nunez, I. Jbir, D. Bianchi, F.C. Meunier, Spectrum baseline artefacts and correction of gas-phase species signal during diffuse reflectance FT-IR analyses of catalysts at variable temperatures, Appl. Catal. A :Gen. 315 (2015) $17-22$. 